\title{
Impact of prior endovascular interventions on outcomes of lower limb bypass surgery: A systematic review and meta-analysis
}

\author{
HAI XIN ${ }^{1 *}$, YONGXIN LI $^{1 *}$, XIAOMEI GUAN ${ }^{1}$, YUEWEI WANG $^{1}$, JUNJUN LIU $^{1}$, \\ XUKUI LIU ${ }^{1}$, JINPING WANG ${ }^{2}$, LIYUAN NIU ${ }^{1}$ and $\mathrm{JUN} \mathrm{LI}^{1}$ \\ Departments of ${ }^{1}$ Vascular Surgery and ${ }^{2}$ Interventional Surgery, \\ The Affiliated Hospital of Qingdao University, Qingdao, Shandong 266003, P.R. China
}

Received April 7, 2020; Accepted July 1, 2020

DOI: $10.3892 / 10.3892 / \mathrm{etm} .2020 .9389$

\begin{abstract}
The aim of this meta-analysis was to evaluate the mortality, amputation and complication rates in patients with peripheral lower limb arterial disease undergoing bypass surgery with or without a prior history of endovascular operation. A systematic literature screen was performed according to the Preferred Reporting Items for Systematic Reviews and Meta-Analyses guidelines on four academic databases, Medline, Scopus, Embase and Cochrane Central Register of Controlled Trials. Out of 1,072 records, six articles involving 11,420 patients (mean age, $68.1 \pm 2.0$ years) met the inclusion criteria. The findings presented a $2 b$ level of evidence (i.e. overall evidence represents data from individual cohort study or low quality randomized controlled trials) and suggested lower mortality, amputation and complication rates for patients undergoing bypass surgery without any history of endovascular operation, compared with those with a history of prior endovascular operation. Moreover, a random-effect meta-analysis suggested a small, positive reduction in mortality (Hedge's $\mathrm{g}=0.08$ ), amputation (Hedge's $\mathrm{g}=0.18$ ) and complication rates (Hedge's $g=0.05$ ) for patients undergoing bypass surgery without any history of endovascular operation. Nevertheless, owing to the scarcity of high-quality data, further studies and randomized clinical trials are needed to confirm these effects.
\end{abstract}

\section{Introduction}

Peripheral arterial disease, particularly in the lower extremities, is one of the most common atherosclerotic morbidities in elderly population groups $(1,2)$, which was reported to

Correspondence to: Dr Jun Li, Department of Vascular Surgery, The Affiliated Hospital of Qingdao University, 16 Jiangsu Road, Qingdao, Shandong 266003, P.R. China

E-mail: zhangy_12345@sina.com

*Contributed equally

Key words: endovascular operation, bypass surgery, claudication affect $>202$ million people worldwide in 2015 (3). Previous epidemiological studies have also suggested a prevalence rate of $\geq 10 \%$ in patients $60-70$ years old (4-6). Typically, peripheral arterial disease in the lower extremities is characterized by an occlusion of the arterial supply due to an atherosclerotic plaque build-up, and presents a range of clinical manifestations, including pain, numbness, weakness and ischemia (7). In severe cases, when occlusion of the artery is $\geq 50 \%$, the risk of developing critical intermittent claudication is increased (6). Furthermore, claudication can result in an abnormal wound healing pattern, which in turn can lead to the development of gangrenous tissue ultimately requiring amputation (8). Swaminathan et al (9) suggested that lower limb amputations can lead to a $48-71 \%$ increase in mortality rates between the first and third year post-amputation.

In severe cases of intermittent claudication, superficial femoral artery or proximal popliteal arteries are the vessels that are most commonly occluded $(10,11)$. Revascularization by means of endovascular operations are usually recommended in such cases to re-establish the depleted blood supply to the unvascularized regions (12). Bisdas et al (13) suggested that minimally invasive endovascular surgeries, such as angioplasty and stenting, should be preferred over bypass surgical approaches due to the faster execution of the procedure, improved post-operative recovery and cost-effectiveness $(14,15)$. Nevertheless, the benefits of endovascular operations are often mitigated by high failure rates, mostly because of their technical nature. In addition, patients with co-existing medical conditions, such as chronic kidney disease, are not eligible for these procedures (16-18).

As a result, the use of conventional bypass surgeries is usually recommended $(19,20)$. A bypass surgery is an intervention during which blood supply is re-routed with a graft to circumvent the occluded area in an artery (21). In the BASIL large-scale, multicenter, randomized controlled trial, Adam et al (15) reported that although neither angioplasty nor bypass surgery had any effect on amputation-free survival, patients undergoing bypass surgery had a longer overall survival. There is currently no consensus regarding whether bypass surgeries should be used as first-line treatment, or only in cases of failure of endovascular operations. For instance, Böckler et al (22) and Nolan et al (23) reported higher complication and amputation rates in patients undergoing bypass 
surgery following a failed stenting operation, compared with patients receiving bypass surgery without prior history of endovascular intervention. However, Uhl et al (24) reported a higher mortality rate in patients receiving bypass surgeries with no prior history of endovascular intervention. To the best of our knowledge, no previous systematic reviews or meta-analyses have evaluated morbidity and mortality-related factors in patients with peripheral arterial disease of the lower extremities undergoing bypass surgeries. Such studies would provide invaluable insight for vascular surgeons and interventional radiologists, and would help support best-practice approaches to minimize morbidity and mortality in patients with lower limb peripheral arterial disease.

Therefore, the aim of the present systematic review and meta-analysis was to evaluate morbidity and mortality-related factors in patients with peripheral arterial disease of the lower extremities undergoing bypass surgeries, according to their history of prior endovascular operation. This review provided comprehensive evidence on mean mortality, amputation and complication rates in patients with peripheral arterial disease undergoing bypass surgery.

\section{Materials and methods}

Data search strategy. The present systematic review and meta-analysis was carried out in adherence to the Preferred Reporting Items for Systematic Reviews and Meta-Analyses (PRISMA) guidelines (25). A PRISMA checklist is presented in Table SI (26).

Four academic databases (Medline, https://www.nlm.nih. gov/bsd/medline.html; Central, https://www.cochranelibrary. com/central/about-central; Embase, https:/www.elsevier. com/solutions/embase-biomedical-research; and Scopus, https://www.scopus.com/) were screened from inception until March 2020 using MeSH keywords. Search terms were used in all academic databases in different combinations, including 'bypass surgery', 'mortality rate', 'amputation rate', 'complications', 'endovascular surgery', 'lower limb occlusion', 'chronic limb threatening ischemia', 'insufficiency' and 'claudication'. The bibliography of the retrieved studies was also manually checked in order to identify any additional relevant studies.

The inclusion criteria were as follows: i) Studies evaluating the morbidity and mortality-related outcomes of patients with peripheral lower limb arterial disease undergoing bypass surgery with or without prior endovascular operation; ii) studies were either randomized controlled trials, quasi-randomized controlled trials, controlled clinical trials, prospective observational trials with control groups or retrospective trials; iii) studies were published in peer-reviewed scientific journals or conference articles; and iv) studies were published in English language.

The selection procedure was independently carried out by two investigators to reduce bias. The following data were extracted from the included studies: i) Author names; ii) sample description (sex, age); iii) country of research; iv) assessed parameters; v) follow-up time; and vi) outcomes. In articles where quantitative data outcomes were not mentioned, attempts were made to contact the corresponding authors for additional data.
Quality assessment. The risk of bias in the included studies was assessed using the Cochrane risk of bias assessment tool for non-randomized controlled trials, also referred to as ROBINS-I (27). The included studies were independently assessed by two investigators. Inadequate randomization, concealment of allocation and reporting of selective outcomes were considered to be major sources of bias (28). In cases of ambiguity, discussions were held between the investigators until a consensus was reached. Moreover, an analysis of the level of evidence was also included, according to the guidelines of the Center for Evidence-Based Medicine (29).

Data analysis. An intragroup meta-analysis of the included studies was carried out using Comprehensive Meta-Analysis version 2.0 (30). The analysis was performed to evaluate the mean mortality, amputation and complication rate outcomes for patients with peripheral lower limb arterial disease undergoing bypass surgery with or without prior endovascular operation. The meta-analysis was conducted based on a random-effect model (31). The individual outcomes were standardized (32) and reported as weighted Hedge's g. The threshold for interpreting the weighted effect sizes were: i) $<0.2$, small effect; ii) 0.2-0.8, medium effect; and iii) $>0.8$, large effect (33). Heterogeneity between the included studies was assessed using $\mathrm{I}^{2}$ statistics. The threshold for interpreting heterogeneity was: i) $0-25 \%$, negligible heterogeneity; ii) $25-75 \%$, moderate heterogeneity; and iii) $\geq 75 \%$, substantial heterogeneity (34).

Sensitivity analyses were performed when potential sources of heterogeneity were identified (35). Accordingly, studies were included if they presented adequate randomization methods, or excluded if they did not. For each evaluated parameter, details of weighted effect size, $95 \%$ CIs, levels of significance and heterogeneity were reported. In addition, publication bias was analyzed using Duval and Tweedie's trim-and fill procedure (36). This non-parametric method trims the studies causing the asymmetry of a funnel plot and estimates the 'true' center of the plot. Thereafter, potential missing studies and the effects they might have on the outcome of a meta-analysis are filled in, allowing their combined effect to be recalculated. In the present review, the $\alpha$-level was set at $\mathrm{P}<0.05$.

\section{Results}

Experimental studies. A preliminary search on four academic databases identified a total of 1,057 studies. An additional 15 studies were included after screening the bibliography of the retrieved articles (Fig. 1). After excluding duplicates and applying the inclusion criteria, a total of six studies were retained. All of the included studies were retrospective clinical trials (22-24,37-39).

Outcomes. Qualitative and quantitative data for patients with peripheral lower limb arterial disease undergoing bypass surgery with or without a prior endovascular operation were then extracted from the six studies (Table I). Mean mortality rate outcomes were assessed in all six studies (22-24,37-39). Of these, three reported a reduction in the mortality rate for patients undergoing bypass surgery without a history of endovascular operation, compared with patients with prior 


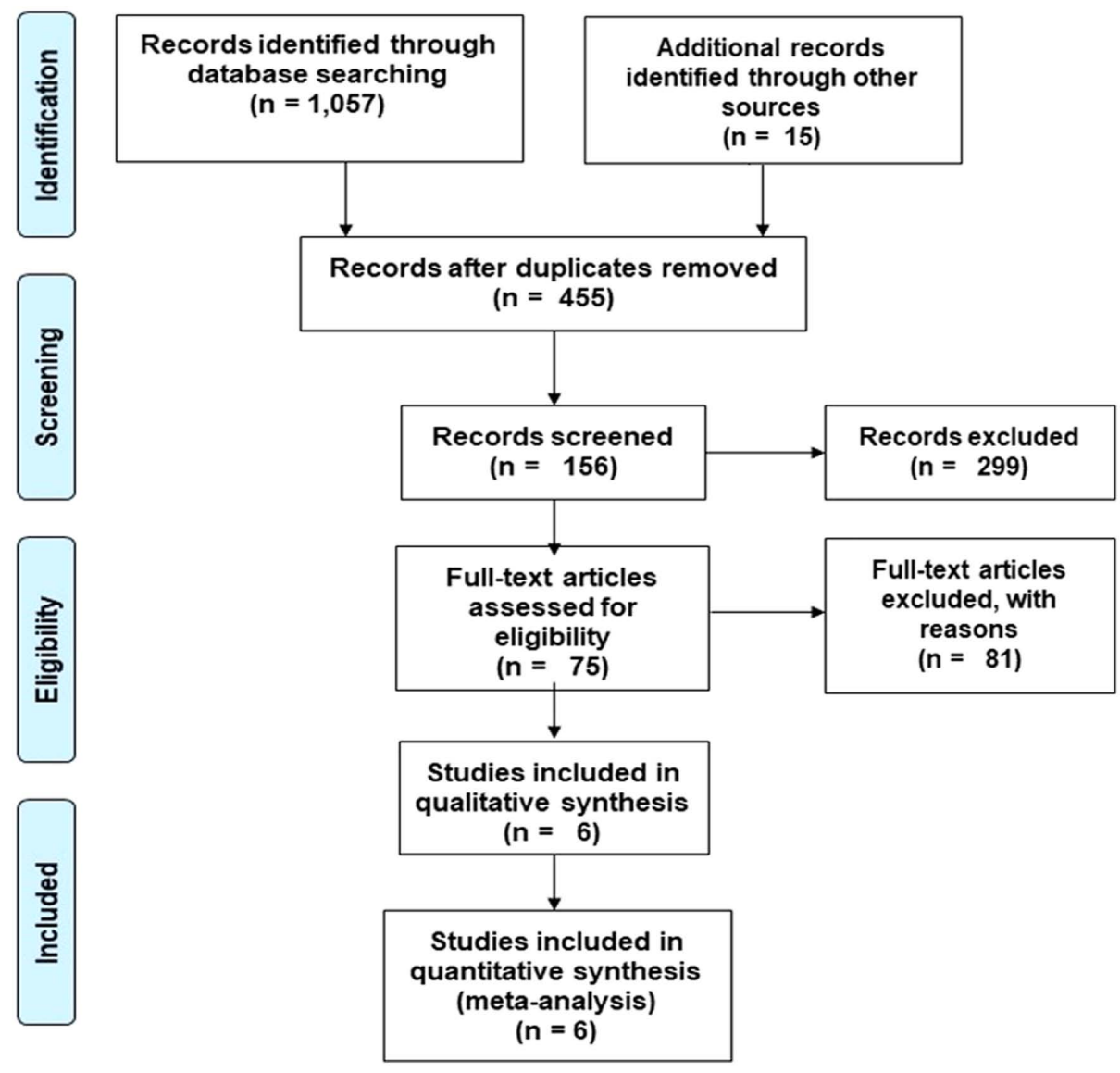

Figure 1. Preferred Reporting Items for Systematic Reviews and Meta-Analyses flow chart for the included studies.

endovascular operation $(23,24,38)$. Moreover, two studies reported an increase in mortality for patients undergoing bypass surgery without prior endovascular operation $(37,39)$. Only one study reported no difference in mortality between the two groups (22).

Similarly, all six studies had evaluated the amputation rate (22-24,37-39). In total, five studies reported a reduction in the mean amputation rate for patients undergoing bypass surgery without prior history of endovascular operation, compared with patients with prior endovascular surgery $(22-24,37,38)$. Only one study reported an increase in the mean rate of amputation in the former group (39).

Lastly, four studies evaluated complication rate outcomes $(22,24,37,39)$. In three studies, the complication rate was reduced in the group with no history of endovascular operation, compared with patients with a prior history $(22,37,39)$. Only one study reported no difference between the two groups (24).

\section{Meta-analysis report}

Mortality rate. The mean mortality rate was assessed in all six studies (22-24,37-39). One study reported that none of the patients died in either of their included groups (22), therefore it was not included in the analysis. The random-effect analysis suggested a small positive, but non-significant effect (Fig. 2), corresponding to a reduction in the mortality rate in patients with no prior history of endovascular operation compared with that in patients with a prior history of endovascular operation (average Hedge's g, 0.08; 95\% CI, -0.41-0.58). There was no heterogeneity between the included studies $\left(\mathrm{I}^{2}, 0 \% ; \mathrm{P}=0.74\right)$.

Amputation rate. The mean amputation rate was assessed in all six studies (22-24,37-39). A small positive, but significant effect was observed (Fig. 3), suggesting a reduction in the amputation rate in patients with no prior history endovascular operation compared with patients with a prior history of endovascular operation (average Hedge's g, 0.18; 95\% CI, 0.02-0.34). Moderate heterogeneity was observed between the studies $\left(\mathrm{I}^{2}, 54.3 \% ; \mathrm{P}=0.02\right)$.

Complication rate. The mean complication rate was assessed four studies $(22,24,37,39)$. The random-effect analysis suggested a small, significant positive effect (Fig. 4), corresponding to a reduction in complications in the group with no prior history endovascular operation as compared to patients with a history of endovascular operation (average Hedge's g, $0.15 ; 95 \%$ CI, 0.003-0.298). There was no heterogeneity between the included studies $\left(\mathrm{I}^{2}, 0 \% ; \mathrm{P}=0.04\right)$.

Participant information. A total of 11,420 patients with peripheral lower limb arterial disease undergoing bypass surgery were evaluated in the studies included in the present review (Table I). Of these, 4,122 patients had a prior history of endovascular operation, whereas 7,298 patients did not. All of the studies assessed included both sexes. The cohort with a history of endovascular operation included 1,524 females and 
516 males. Likewise, the group with no history of endovascular operation consisted of 2,451 female patients and 4,748 male patients. However, two studies did not mention the sex of their patients $(22,24)$. Overall, the mean age of the included participants was $68.1 \pm 2.0$ years. The mean age was similar in patients with a history of endovascular operation and those without $(67.2 \pm 1.8$ vs. $69.0 \pm 2.0$ years, respectively).

Follow-up assessment.In four of the included studies, a follow-up assessment was carried out after only one month $(34,36)$ or after 12 months $(23,38)$. In one study, follow-up assessment took place 8 months after bypass surgery (Table I) (22).

Risk of bias. The overall risk of bias in all the included studies is high. The highest risk of bias was observed due to confounding and selection bias. A $2 b$ level of evidence was observed for the included studies based on their experimental design (Table II; Fig. 5).

Publication bias. The trim-and-fill procedure identified two missing studies on the right-hand side of the mean effect (Fig. 6). This means that the trim-and-fill method first trimmed the studies that caused the funnel plot's asymmetry so that the overall effect estimate produced by the remaining studies can be considered minimally impacted by publication bias. Thereafter, the method filled the imputed missing studies on the right side of the funnel plot based on the bias-corrected overall estimate. According to a random-effects model, the point estimates for the evaluated parameters was 0.18 (95\% CI, 0.002-0.35). These values represent the overall effect size of all the parameters in the included studies before the assessment of publication bias. Using the trim-and-fill procedure, the most extreme effect sizes were trimmed from the left side of the funnel plot and filled on the right side of the funnel plot to obtain funnel plot symmetry. The trim and fill procedure reported a point estimate of 0.21 (95\% CI, 0.03-0.38). This corrected effect size estimate is obtained by computing the meta-analytic estimate based on the observed and imputed effect sizes. Here, the difference in between the two-point estimates is 0.03 . Since the bias has been adjusted in the positive domain, it can be interpreted that the publication bias existed in the negative domain i.e. on the left side of the funnel plot (40).

\section{Discussion}

To the best of our knowledge, the present review was the first to summarize the current state of evidence concerning morbidity and mortality-related outcomes in patients with peripheral arterial disease of the lower extremities undergoing bypass surgery, according to their history of endovascular surgery. The present study reported a reduction in mean mortality, amputation and complication rates in patients receiving bypass surgery without any prior history of any endovascular operation.

The management of peripheral arterial disease is a challenging factor for vascular surgeons worldwide $(41,42)$. Several studies have outlined the clinical benefits of endovascular surgery on critical intermittent claudication in the lower extremities $(43,44)$. For example, Tielliu et al $(45)$ suggested 
Studyname

Statistics for each study

Hedges's g and $95 \% \mathrm{Cl}$

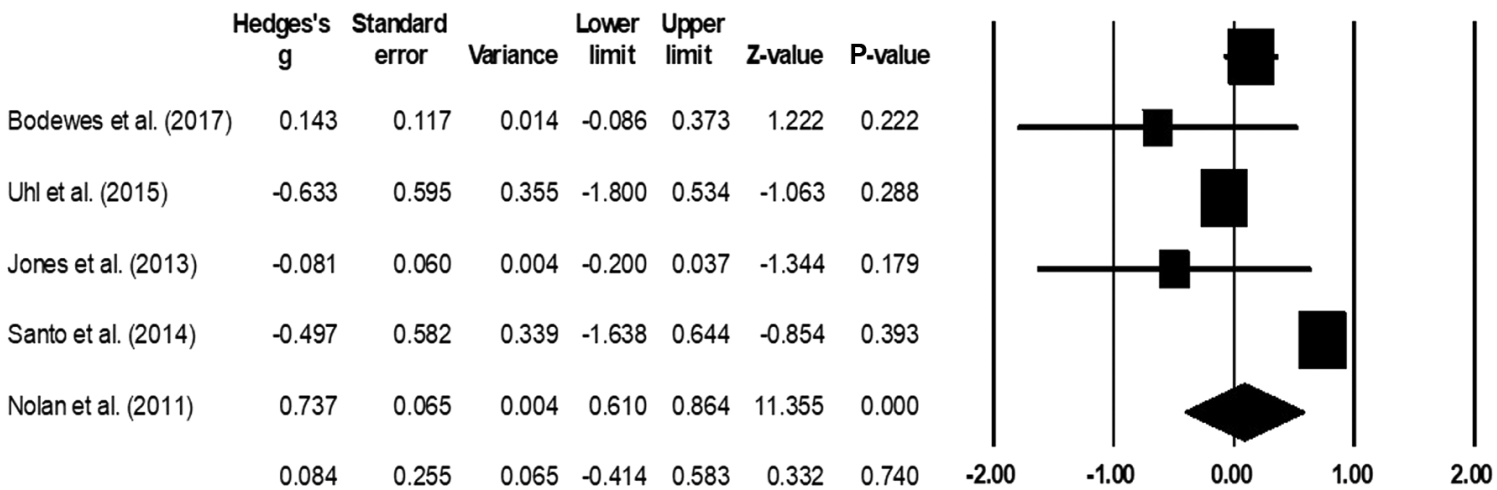

Figure 2. Mean mortality rate for patients with peripheral lower limb arterial disease. Data are represented as a forest plot comparing patients undergoing bypass surgery with prior history of endovascular operation vs. patients without prior history. Weighted effect sizes are presented as filled squares and $95 \% \mathrm{CI}$ as whiskers, where the size of the squares is proportional to the Hedge's g effect observed in the corresponding study. The overall effect size is represented as a filled diamond. A negative Hedge's $g$ indicates reduced mortality rate in the group with prior history of endovascular operation, whereas a positive Hedge's $g$ is indicative of reduced mortality rate for the group with no prior history of endovascular operation.

Study name

\begin{tabular}{|c|c|c|c|c|c|c|c|}
\hline & $\begin{array}{l}\text { Hedges's } \\
\mathbf{g}\end{array}$ & $\begin{array}{l}\text { Standard } \\
\text { error }\end{array}$ & Variance & $\begin{array}{l}\text { Lower } \\
\text { limit }\end{array}$ & $\begin{array}{l}\text { Upper } \\
\text { limit }\end{array}$ & Z-value & P-value \\
\hline Bodewes et al. (2017) & 0.085 & 0.080 & 0.006 & -0.071 & 0.241 & 1.063 & 0.288 \\
\hline Uhl et al. (2015) & -0.148 & 0.460 & 0.212 & -1.050 & 0.754 & -0.322 & 0.747 \\
\hline Jones et al. (2013) & 0.209 & 0.065 & 0.004 & 0.082 & 0.335 & 3.235 & 0.001 \\
\hline Santo et al. (2014) & -0.269 & 0.306 & 0.094 & -0.870 & 0.331 & -0.879 & 0.379 \\
\hline Nolan et al. (2011) & 0.223 & 0.058 & 0.003 & 0.109 & 0.338 & 3.823 & 0.000 \\
\hline \multirow[t]{2}{*}{ Böckler et al. (2005) } & 1.348 & 0.383 & 0.147 & 0.597 & 2.098 & 3.519 & 0.000 \\
\hline & 0.187 & 0.083 & 0.007 & 0.025 & 0.349 & 2.263 & 0.024 \\
\hline
\end{tabular}

Hedges's g and $95 \% \mathrm{Cl}$

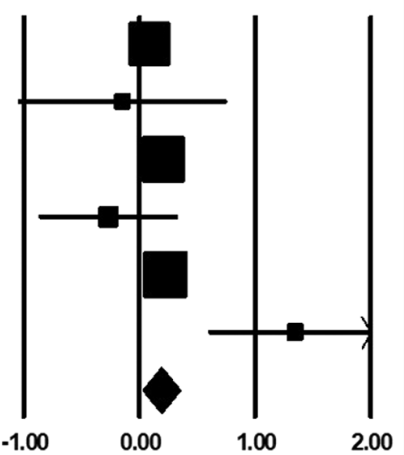

Figure 3. Mean amputation rate for patients with peripheral lower limb arterial disease. Data are represented as a forest plot comparing patients undergoing bypass surgery with prior history of endovascular operation vs. patients without prior history. Weighted effect sizes are presented as filled squares and $95 \% \mathrm{CI}$ as whiskers, the size of the squares is proportional to the Hedge's g effect observed in the corresponding study. The overall effect size is represented as a filled diamond. A negative Hedge's $g$ indicates reduced amputation rate in the group with prior history of endovascular operation, whereas a positive Hedge's $g$ is indicative of reduced amputation rate for the group with no prior history of endovascular operation.

Study name

$\begin{array}{lcccccccc} & \begin{array}{c}\text { Hedges's } \\ \mathrm{g}\end{array} & \begin{array}{c}\text { Standard } \\ \text { error }\end{array} & \text { Variance } & \begin{array}{c}\text { Lower } \\ \text { limit }\end{array} & \begin{array}{c}\text { Upper } \\ \text { limit }\end{array} & \text { Z-Value } & \text { p-Value } \\ \text { Bodewes et al.(2017) } & 0.116 & 0.090 & 0.008 & -0.060 & 0.292 & 1.291 & 0.197 \\ & & & & & & & \\ \text { Uhl et al. (2015) } & 0.470 & 0.782 & 0.612 & -1.063 & 2.004 & 0.601 & 0.548 \\ \text { Santo et al. (2014) } & 0.216 & 0.158 & 0.025 & -0.093 & 0.525 & 1.370 & 0.171 \\ \text { BödNer et al. (2005) } & 0.254 & 0.305 & 0.093 & -0.344 & 0.851 & 0.832 & 0.405 \\ & 0.150 & 0.075 & 0.006 & 0.003 & 0.298 & 1.999 & 0.046\end{array}$

\section{Hedges's $\mathrm{g}$ and $95 \% \mathrm{C}$}

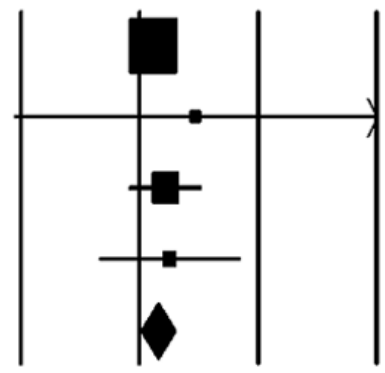

$\begin{array}{rrrrr}-2.00 & -1.00 & 0.00 & 1.00 \quad 2.00\end{array}$

Figure 4. Mean complication rate for patients with peripheral lower limb arterial disease. Data are represented as a forest plot comparing patients undergoing bypass surgery with prior history of endovascular operation vs. patients without prior history. Weighted effect sizes are presented as filled squares and $95 \%$ CI as whiskers, the size of the squares is proportional to the Hedge's g effect observed in the corresponding study. The overall effect size is represented as a filled diamond. A negative Hedge's g represents an increased complication rate in patients with prior history of endovascular operation, whereas a positive Hedge's $g$ indicates a reduced complication rate for the group with no prior history of endovascular operation. 
Table II. Bias risk in the analyzed studies.

\begin{tabular}{|c|c|c|c|c|c|c|c|c|}
\hline Author, year & $\begin{array}{l}\text { Confounding } \\
\text { bias }\end{array}$ & $\begin{array}{l}\text { Selection } \\
\text { bias }\end{array}$ & $\begin{array}{l}\text { Deviation } \\
\text { from intended } \\
\text { intervention }\end{array}$ & $\begin{array}{c}\text { Missing } \\
\text { data }\end{array}$ & $\begin{array}{l}\text { Measurement } \\
\text { in outcome }\end{array}$ & $\begin{array}{l}\text { Selection } \\
\text { of reported } \\
\text { result }\end{array}$ & $\begin{array}{c}\text { Classification of } \\
\text { intervention }\end{array}$ & (Refs.) \\
\hline $\begin{array}{l}\text { Bodewes et al, } \\
2017\end{array}$ & High & Low & High & Low & Low & Low & Low & (37) \\
\hline $\begin{array}{l}\text { Uhl et al, } \\
2015\end{array}$ & High & Low & Low & Low & Low & Low & Low & (24) \\
\hline $\begin{array}{l}\text { Santo et al, } \\
2014\end{array}$ & Unclear & Unclear & Low & Low & Low & Low & Low & (39) \\
\hline $\begin{array}{l}\text { Jones et al, } \\
2013\end{array}$ & Unclear & Low & High & Low & Low & Unclear & Low & (38) \\
\hline $\begin{array}{l}\text { Nolan et al, } \\
2011\end{array}$ & Unclear & High & Low & Low & Low & High & Unclear & (23) \\
\hline $\begin{array}{l}\text { Böckler et al, } \\
2005\end{array}$ & Unclear & High & Low & Low & Low & Low & Low & (22) \\
\hline
\end{tabular}

All included studies were analyzed using the Cochrane risk of bias assessment tool for non-randomized controlled trials. A level of evidence of $2 b$ was observed in each study.

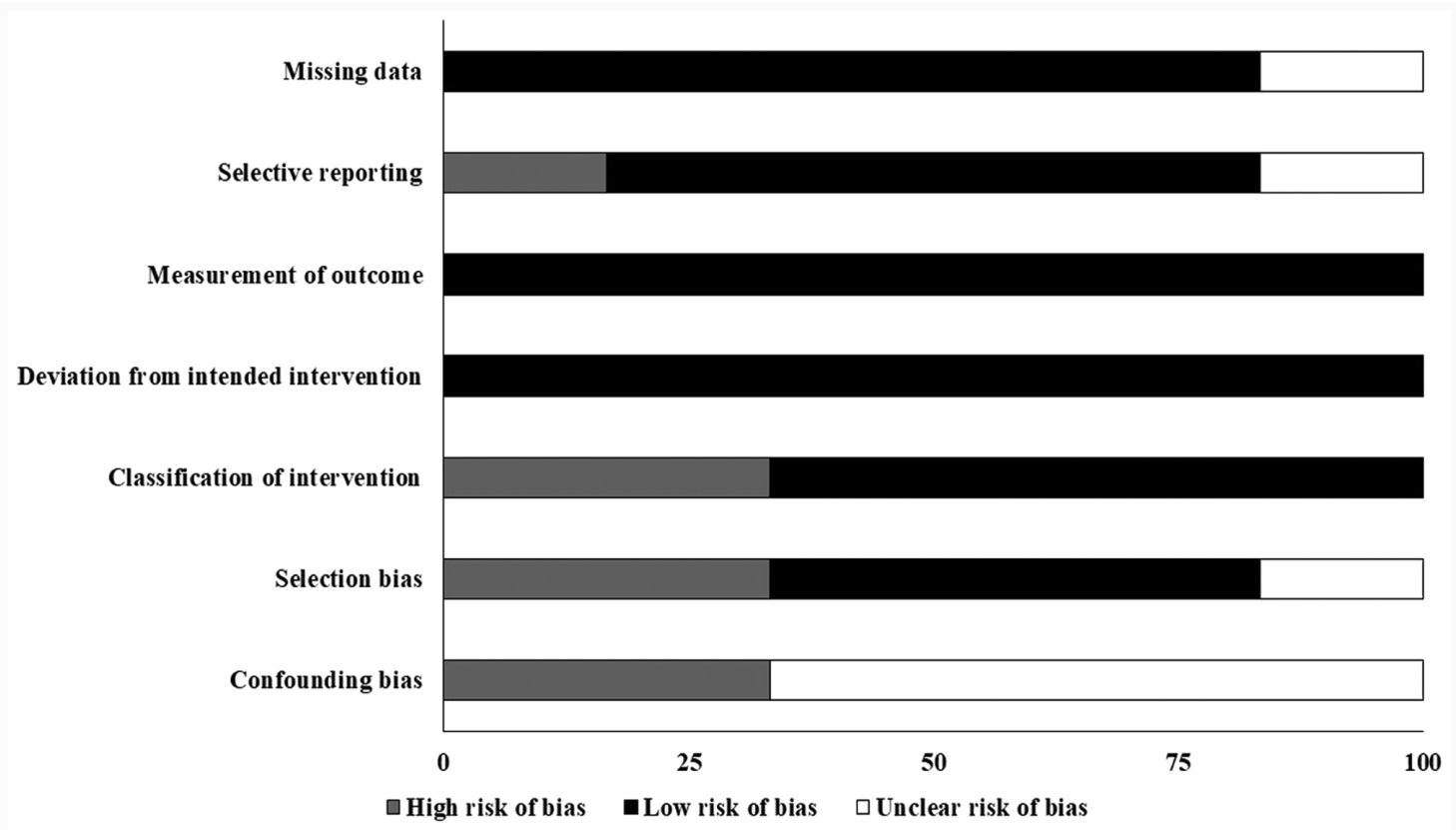

Figure 5. Risk of bias in the included studies. Bias risk was assessed using the Cochrane risk of bias assessment for randomized controlled trials.

that the minimally invasive nature of endovascular operations could reduce post-operative morbidity in patients with popliteal artery occlusion (45). Similarly, Adam et al (15) reported superior cost-effectiveness, repeatability and collateral preservation, where collateral arteries are preserved during the surgery to prevent re-occurrence of symptoms in cases of re-occlusion of the angioplasty site, with endovascular approaches, such as balloon angioplasty (46). However, the authors cautioned over the conventional use of endovascular surgery as first-line treatment for peripheral arterial disease, reporting clinical failure rate of $\sim 25 \%$ with this approach (15).
Böckler et al (22) also reported that endovascular operations below the inguinal ligament carried a very high risk of failure. Several factors contribute to the high risk of failure observed with endovascular operation, including lower pulsating blood flow in the infra-popliteal arteries, shorter stent length, technicality of the approach and the complex nature of peripheral arterial disease $(44,47)$. The literature recommends that under the circumstances of high failure rates with endovascular interventions, bypass surgeries must be performed to reinstate blood supply to the avascular parts $(15,22)$. Nevertheless, recent studies have suggested that secondary bypass surgery 


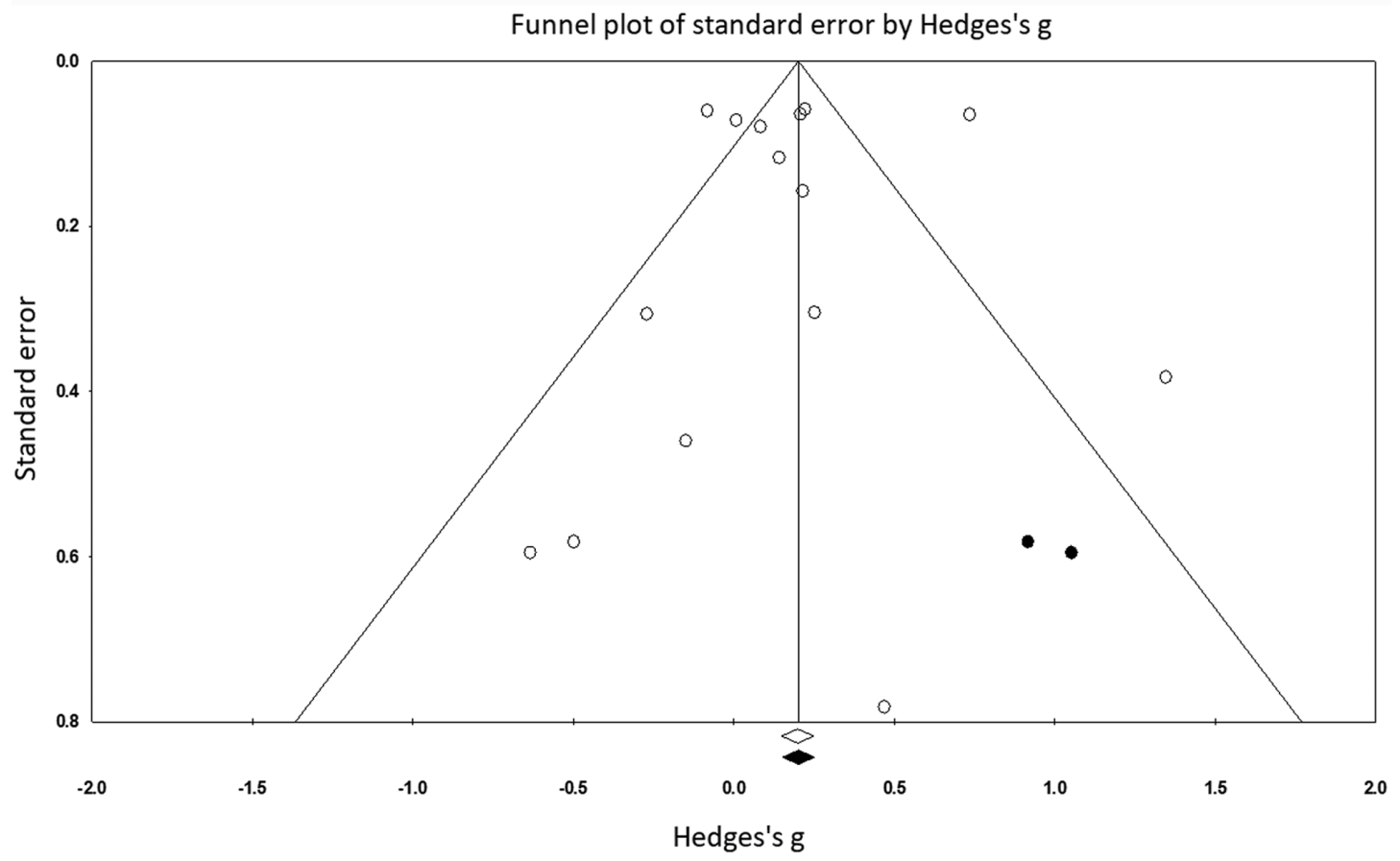

Figure 6. Publication bias funnel plot. Analyzed effects are represented as circles. Boundaries of the plot mark the area where $95 \%$ of all the effects would reside if there were no publication bias. Vertical midline denotes the mean standardized effect of zero. The empty circles represent individual effect sizes of the included studies, whereas the filled circles represent the imputed studies that have been filled with the trim and fill procedure.

after a failed endovascular attempt could result in an increase in morbidity and mortality (48).

In a retrospective study, Bodewes et al (37) analyzed patients undergoing primary $(n=2,031)$ or secondary bypass surgery $(n=3,102)$. Patients undergoing secondary bypass surgery had a higher rate of complications (as demonstrated by a high major adverse cardiovascular event score), secondary respiratory problems and urinary tract infections, compared with those undergoing a primary bypass surgery. The authors further hypothesized that a failed endovascular operation may introduce anatomical restrictions such as damage to inflow or runoff vessels due to previous procedures, which will eventually occlude arterial inflow or compromise blood vessel run-off due to embolism, in turn resulting in the increased complication rate in patients receiving secondary bypass surgery. Similarly, Böckler et al (22) reported an increase in complication rate for the group receiving secondary bypass surgery $(40 \%)$, compared with the group with no history of an endovascular operation $(17 \%)$. The authors hypothesized that stenting failure could damage the endothelial layer of the artery, which could in turn promote a thrombotic growth, eventually worsening patient prognosis. Moreover, Santo et al (39) and Uhl et al (24) also reported an increase in the mean complication rates for the patients receiving a bypass surgery with prior history of endovascular operation compared with patients receiving a secondary bypass operation. The present meta-analysis is in agreement with these findings and suggested a small reduction in the complication rates in patients receiving bypass surgery without any prior history of endovascular operation.

Furthermore, an increase in amputation rate has also been documented in patients receiving secondary bypass surgery (22-24,38,39). For instance, Nolan et al (23) reported an increased rate of amputation in patients receiving bypass surgery after an ipsilateral endovascular intervention (31\%) compared with patients receiving primary bypass surgery $(20 \%)$. This increased rate of amputation following secondary bypass surgery could be explained by two important mechanisms. Firstly, a higher rate of complications associated with wound infection in patients with a prior history of endovascular intervention, with $\leq 1.5$ times higher rate of infection compared with patients with no prior history of endovascular intervention (37) and co-existing medical conditions, such as diabetes or chronic kidney disease, might impair the post-operative healing process and increase the risk of amputation. Secondly, as suggested by Uhl et al (24), a delay in the execution of a secondary bypass intervention after a failed endovascular operation could also increase the development of gangrenous tissue and increase the risk of amputation. The present meta-analysis is in line with these findings and reported a small reduction in amputation rates in patients receiving bypass surgery without prior history of endovascular operation.

Lastly, the present study also suggested a reduction in the mortality rate in patients receiving bypass surgery without prior history of endovascular operation $(23,37)$. Bodewes et al $(37)$ suggested that an increased rate of cardiovascular adverse events and renal insufficiency during secondary bypass surgeries was a major determinant underlying the increased mortality rate in these patients. A reduced mortality rate was observed in patients undergoing primary bypass surgeries (3.7\%), compared with patients receiving a bypass after a failed endovascular operation (4.3\%). This finding was also confirmed in the present meta-analysis. Notably, a small reduction in the mean mortality rate was observed in patients receiving a primary bypass, compared with those receiving secondary bypass surgery.

Despite the novelty of this present meta-analysis, a few limitations remain. Firstly, registration of this systematic 
review was not performed in a prospective registry, such as Prospero or Open Science Framework, which may undermine the validity of this review (49). Moreover, the broad inclusion criteria used in the present study led to the inclusion of a wide range of studies, in which patients received secondary bypass surgery after different types of endovascular intervention, such as angioplasty, stenting and after a failed initial bypass surgery. This may account for the moderate heterogeneity observed in the meta-analysis of amputation rates. Therefore, the results of this meta-analysis report should be interpreted with caution. In addition, due to the paucity of data, separate analyses for failed endovascular operations performed in ipsilateral extremities and contralateral extremities could not be conducted. Nolan et al (23), for instance, reported a higher amputation and graft occlusion rate for secondary bypass surgeries carried out following a failed endovascular operation on the ipsilateral leg. Lastly, again due to the limited availability of data, a cost-benefit analysis of bypass surgeries performed with or without prior endovascular operations was not carried out. An evaluation of these parameters would prove extremely beneficial for healthcare communities, particularly in low-and middle-income countries where morbidity and mortality associated with peripheral arterial disease are the highest (3). Therefore, future studies should address these gaps by performing subgroup analyses, and the findings should be shared in open-access repositories.

In conclusion, this systematic review and meta-analysis provided a $2 b$ level of evidence demonstrating reduced mean mortality, amputation and complication rates in patients with lower limb peripheral arterial disease undergoing bypass surgery without prior history of endovascular operations, as compared with patients with a history of endovascular operations. The findings from the current meta-analysis may provide insight into the development of best-practice emergency care guidelines for the management of peripheral arterial disease.

\section{Acknowledgements}

Not applicable.

\section{Funding}

No funding was received.

\section{Availability of data and materials}

The datasets used and/or analyzed during the current study are available from the corresponding author on reasonable request.

\section{Authors' contributions}

HX and YL conceived and designed the study. XG, YW, JLiu, XL, JW, LN and JLi collected the data, performed the literature search and conducted the meta-analysis. HX and YL were involved in the writing the manuscript. All authors read and approved the final manuscript.

\section{Ethics approval and consent to participate}

Not applicable.

\section{Patient consent for publication}

Not applicable.

\section{Competing interests}

The authors declare that they have no competing interests.

\section{References}

1. Dhaliwal G and Mukherjee D: Peripheral arterial disease: Epidemiology, natural history, diagnosis and treatment. Int $\mathbf{J}$ Angiol 16: 36-44, 2007.

2. Fowkes FG, Rudan D, Rudan I, Aboyans V, Denenberg JO, McDermott MM, Norman PE, Sampson UK, Williams LJ, Mensah GA and Criqui MH: Comparison of global estimates of prevalence and risk factors for peripheral artery disease in 2000 and 2010: A systematic review and analysis. Lancet 382: 1329-1340, 2013.

3. Song P, Rudan D, Zhu Y, Fowkes FJ, Rahimi K, Fowkes FG and Rudan I: Global, regional, and national prevalence and risk factors for peripheral artery disease in 2015: An updated systematic review and analysis. Lancet Glob Health 7: e1020-e1030, 2019.

4. Criqui $\mathrm{MH}$ and Aboyans V: Epidemiology of peripheral artery disease. Circ Res 116: 1509-1526, 2015.

5. Fowkes FG, Aboyans V, Fowkes FJI, McDermott MM, Sampson UK and Criqui MH: Peripheral artery disease: Epidemiology and global perspectives. Nat Rev Cardiol 14: 156-170, 2017.

6. Shu J and Santulli G: Update on peripheral artery disease: Epidemiology and evidence-based facts. Atherosclerosis 275: 379-381, 2018.

7. Dieter RS, Chu WW, Pacanowski JP Jr, McBride PE and Tanke TE: The significance of lower extremity peripheral arterial disease. Clin Cardiol 25: 3-10, 2002.

8. Olivieri B, Yates TE, Vianna S, Adenikinju O, Beasley RE and Houseworth J: On the cutting edge: Wound care for the endovascular specialist. Semin Intervent Radiol 35: 406-426, 2018.

9. Swaminathan A, Vemulapalli S, Patel MR and Jones WS: Lower extremity amputation in peripheral artery disease: Improving patient outcomes. Vasc Health Risk Manag 10: 417-424, 2014.

10. Kasapis $\mathrm{C}$ and Gurm HS: Current approach to the diagnosis and treatment of femoral-popliteal arterial disease. A systematic review. Curr Cardiol Rev 5: 296-311, 2009.

11. McDermott MM, Liu K, Carroll TJ, Tian L, Ferrucci L, Li D, Carr J, Guralnik JM, Kibbe M, Pearce WH, et al: Superficial femoral artery plaque and functional performance in peripheral arterial disease: Walking and leg circulation study (WALCS III). JACC Cardiovasc Imaging 4: 730-739, 2011.

12. Abu Dabrh AM, Steffen MW, Asi N, Undavalli C, Wang Z, Elamin MB, Conte MS and Murad MH: Bypass surgery versus endovascular interventions in severe or critical limb ischemia. J Vasc Surg 63: 244-253.e11, 2016.

13. Bisdas T, Borowski M, Stavroulakis K, Torsello G and CRITISCH Collaborators: Endovascular therapy versus bypass surgery as first-line treatment strategies for critical limb ischemia: Results of the interim analysis of the CRITISCH registry. JACC Cardiovasc Interv 9: 2557-2565, 2016.

14. Barshes NR, Chambers JD, Cohen J and Belkin M; Model To Optimize Healthcare Value in Ischemic Extremities 1 (MOVIE) Study Collaborators: Cost-effectiveness in the contemporary management of critical limb ischemia with tissue loss. J Vasc Surg 56: 1015-1024.e1, 2012.

15. Adam DJ, Beard JD, Cleveland T, Bell J, Bradbury AW, Forbes JF, Fowkes FG, Gillepsie I, Ruckley CV, Raab G, et al: Bypass versus angioplasty in severe ischaemia of the leg (BASIL): Multicentre, randomised controlled trial. Lancet 366: 1925-1934, 2005.

16. Baird RN, Bradley MD and Murphy KP: Tibioperoneal angioplasty and bypass. Acta Chir Belg 103: 383-387, 2003.

17. Salas CA, Adam DJ, Papavassiliou VG and London NJ: Percutaneous transluminal angioplasty for critical limb ischaemia in octogenarians and nonagenarians. Eur J Vasc Endovasc Surg 28: 142-145, 2004.

18. Treiman GS: Subintimal angioplasty for infrainguinal occlusive disease. Surg Clin North Am 84: 1365-1380, viii, 2004. 
19. Barakate MS, Bannon PG, Hughes CF, Horton MD, Callaway A and Hurst T: Emergency surgery after unsuccessful coronary angioplasty: A review of 15 years' experience. Ann Thorac Surg 75: 1400-1405, 2003.

20. Poyen V, Silvestri M, Labrunie P and Valeix B: Indications of coronary angioplasty and stenting in 2003: What is left to surgery? J Cardiovasc Surg (Torino) 44: 307-312, 2003.

21. Wohlgemuth WA, Safonova O, Engelhardt M, Freitag M, Wölfle K and Kirchhof K: Improvement of the quality of life concerning the health of patients with peripheral arterial disease (PAD) after successful bypass surgery. Vasa 37: 338-344, 2008.

22. Böckler D, Blaurock P, Mansmann U, Schwarzbach M, Seelos R, Schumacher H and Allenberg JR: Early surgical outcome after failed primary stenting for lower limb occlusive disease. J Endovasc Ther 12: 13-21, 2005.

23. Nolan BW, De Martino RR, Stone DH, Schanzer A, Goodney PP, Walsh DW and Cronenwett JL; Vascular Study Group of New England: Prior failed ipsilateral percutaneous endovascular intervention in patients with critical limb ischemia predicts poor outcome after lower extremity bypass. J Vasc Surg 54: 730-735; discussion 735-736, 2011

24. Uhl C, Hock C, Betz T, Bröckner S, Töpel I and Steinbauer M: The impact of infrainguinal endovascular interventions on the results of subsequent femoro-tibial bypass procedures: A retrospective cohort study. Int J Surg 13: 261-266, 2015.

25. Moher D, Liberati A, Tetzlaff J, Altman DG and PRISMA Group: Preferred reporting items for systematic reviews and meta-analyses: The PRISMA statement. PLoS Med 6: e1000097, 2009.

26. Liberati A, Altman DG, Tetzlaff J, Mulrow C, Gøtzsche PC, Ioannidis JP, Clarke M, Devereaux PJ, Kleijnen J and Moher D: The PRISMA statement for reporting systematic reviews and meta-analyses of studies that evaluate health care interventions: Explanation and elaboration. PLoS Med 6: e1000100, 2009.

27. Sterne JA, Hernán MA, Reeves BC, Savović J, Berkman ND, Viswanathan M, Henry D, Altman DG, Ansari MT, Boutron I, et al: ROBINS-I: A tool for assessing risk of bias in non-randomised studies of interventions. BMJ 355: i4919, 2016.

28. Viswanathan M, Ansari MT, Berkman ND, Chang S, Hartling L, McPheeters M, Santaguida PL, Shamliyan T, Singh K, Tsertsvadze A and Treadwell JR: Assessing the risk of bias of individual studies in systematic reviews of health care interventions. In: Methods Guide for Effectiveness and Comparative Effectiveness Reviews. Agency for Healthcare Research and Quality, Rockville, MD, 2008.

29. Burns PB, Rohrich RJ and Chung KC: The levels of evidence and their role in evidence-based medicine. Plast Reconstr Surg 128: 305-310, 2011

30. Bax L, Yu LM, Ikeda N and Moons KG: A systematic comparison of software dedicated to meta-analysis of causal studies. BMC Med Res Methodol 7: 40, 2007.

31. Higgins JP, Thompson SG and Spiegelhalter DJ: A re-evaluation of random-effects meta-analysis. J R Stat Soc Ser A Stat Soc 172: 137-159, 2009.

32. Chinn S: A simple method for converting an odds ratio to effect size for use in meta-analysis. Stat Med 19: 3127-3131, 2000.

33. Rosenthal R: Parametric measures of effect size. In: The Handbook of Research Synthesis. Russell Sage Foundation, New York, NY, pp231-244, 1994.

34. Higgins JP and Thompson SG: Quantifying heterogeneity in a meta-analysis. Stat Med 21: 1539-1558, 2002

35. Petitti DB: Approaches to heterogeneity in meta-analysis. Stat Med 20: 3625-3633, 2001.
36. Duval S and Tweedie R: Trim and fill: A simple funnel-plot-based method of testing and adjusting for publication bias in meta-analysis. Biometrics 56: 455-463, 2000.

37. Bodewes TC, Ultee KH, Soden PA, Zettervall SL, Shean KE, Jones DW, Moll FL and Schermerhorn ML: Perioperative outcomes of infrainguinal bypass surgery in patients with and without prior revascularization. J Vasc Surg 65: 1354-1365.e2, 2017.

38. Jones DW, Schanzer A, Zhao Y, MacKenzie TA, Nolan BW, Conte MS and Goodney PP; Vascular Study Group of New England: Growing impact of restenosis on the surgical treatment of peripheral arterial disease. J Am Heart Assoc 2: e000345, 2013.

39. Santo VJ, Dargon P, Azarbal AF, Liem TK, Mitchell EL, Landry GJ and Moneta GL: Lower extremity autologous vein bypass for critical limb ischemia is not adversely affected by prior endovascular procedure. J Vasc Surg 60: 129-135, 2014

40. Shi L and Lin L: The trim-and-fill method for publication bias: Practical guidelines and recommendations based on a large database of meta-analyses. Medicine (Baltimore) 98: e15987, 2019.

41. Hirsch AT, Allison MA, Gomes AS, Corriere MA, Duval S, Ershow AG,Hiatt WR, Karas RH,Lovell MB,McDermott MM, et al: A call to action: Women and peripheral artery disease: A scientific statement from the American heart association. Circulation 125: 1449-1472, 2012.

42. Zachary I and Morgan RD: Therapeutic angiogenesis for cardiovascular disease: Biological context, challenges, prospects. Heart 97: 181-189, 2011

43. Farber A, Rosenfield K and Menard M: The BEST-CLI trial: A multidisciplinary effort to assess which therapy is best for patients with critical limb ischemia. Tech Vasc Interv Radiol 17: 221-224, 2014.

44. Henry M, Henry I, Klonaris C and Hugel M: Clinical experience with the OptiMed sinus stent in the peripheral arteries. J Endovasc Ther 10: 772-779, 2003.

45. Tielliu IF, Verhoeven EL, Zeebregts CJ, Prins TR, Span MM and van den Dungen JJ: Endovascular treatment of popliteal artery aneurysms: Results of a prospective cohort study. J Vasc Surg 41: 561-567, 2005.

46. Tunis SR, Bass EB and Steinberg EP: The use of angioplasty, bypass surgery, and amputation in the management of peripheral vascular disease. N Engl J Med 325: 556-562, 1991.

47. Mewissen MW: Self-expanding nitinol stents in the femoropopliteal segment: Technique and mid-term results. Tech Vasc Interv Radiol 7: 2-5, 2004.

48. Hossain S, Leblanc D, Farber A, Power AH, DeRose G, Duncan A and Dubois L: Editor's choice-infrainguinal bypass following failed endovascular intervention compared with primary bypass: A systematic review and meta-analysis. Eur J Vasc Endovasc Surg 57: 382-391, 2019.

49. PLoS Medicine Editors: Best practice in systematic reviews: The importance of protocols and registration. PLoS Med 8: e1001009, 2011.

This work is licensed under a Creative Commons Attribution-NonCommercial-NoDerivatives 4.0 International (CC BY-NC-ND 4.0) License. 